\title{
硝酸蒸解法に依るパルプ製造に關する研究(第10報) 本邦産山毛㩧林、楢村の硝酸蒸解に就きて
}

\author{
下田功・久村次即・藤原蓬二
}

(炤和 14 脌 8 月 5 日受理)

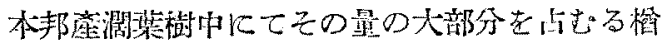

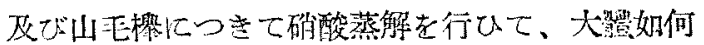

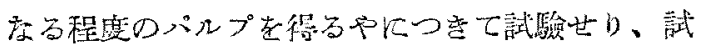
料上しては鋜片在用ひ、乙礼を $3 \mathrm{~cm}$ 四方位に切

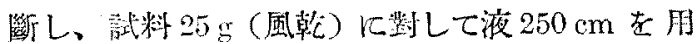

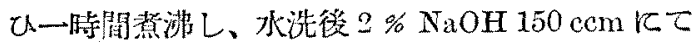
1 時間替沸与。鎠片の厚さは $0.5 \sim 1 \mathrm{~mm}$ なり、試 料以外は全部縃對乾燥として計算す。

\section{(A) 山北榴の場合}

試棹の水今心 $10.88 \%$ にして、确酸のみと、稀混 酸にて蒸留せり。

(1) 硝酸の子の堬合

\begin{tabular}{|c|c|c|c|c|c|c|}
\hline 料 & 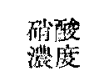 & 步留 & $\begin{array}{l}\text { 收得 } \\
\text { 得 }\end{array}$ & 彷分 & $\begin{array}{l}\text { ペント } \\
\text { ザン人 }\end{array}$ & \\
\hline & $6 \%$ & $11 \mathrm{~g}$ & $49.3 \%$ & - & $8.49 \%$ & \\
\hline & $8 \%$ & $10 \mathrm{~g}$ & $44.8 \%$ & $0.31 \%$ & $7.66 \%$ & $89.75 \%$ \\
\hline & $0 \%$ & $9.2 \mathrm{~g}$ & $41.3 \%$ & $0.28 \%$ & $6.58 \%$ & $90.40 \%$ \\
\hline & & $5 g$ & $42.5 \%$ & $28 \%$ & $7.55 \%$ & \\
\hline
\end{tabular}

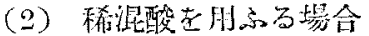

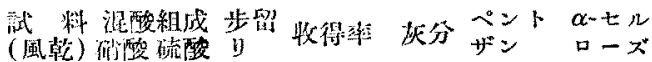
$25 \mathrm{~g} \quad 5 \% \quad 1 \% \quad \begin{array}{lllllll}5.2 \mathrm{~g} & 41.2 \% & 0.24 \% & 8.80 \% & 90.60 \%\end{array}$

$25 \mathrm{~g} \quad 7 \% \quad 1 \% \quad 8.8 \mathrm{~g} \quad 39.4 \% \quad 0.25 \% \quad 7.66 \% \quad 01.05 \%$ $25 \mathrm{~g} \quad 9 \% \quad 1 \% \quad 7.8 \mathrm{~g} \quad 35.0 \% \quad 0.24 \% \quad 7.60 \% \quad 91.05 \%$ $25 \mathrm{~g} 11 \% 1 \% \sim \sim 0.26 \% 6.58 \% 91.00 \%$ $25 \mathrm{~g} \quad 6 \% \quad 2 \% \quad 8.0 \mathrm{~g} \quad 35.5 \% \quad 0.24 \% \quad 6.88 \% \quad 91.30 \%$ $25 \mathrm{~g} \quad 8 \% \quad 2 \% \quad 8.5 \mathrm{~g} \quad 38.1 \% \quad 0.25 \% \quad 6.74 \% \quad 91.25 \%$ $25 \mathrm{~g} \quad 10 \% \quad 2 \% \quad 7.5 \mathrm{~g} \quad 33.6 \% \quad 0.29 \% \quad 5.21 \% \quad 91.10 \%$ $25 \mathrm{~g} \quad 12 \% \quad 2 \% \quad 6.7 \mathrm{~g} \quad 30.0 \% \quad 0.26 \% \quad 4.98 \% \quad 91.68 \%$ $25 \mathrm{~g} \quad 5 \% \quad 3 \% \quad 7.3 \mathrm{~g} \quad 32.7 \% \quad 0.24 \% \quad 6.32 \% \quad 40.70 \%$ $25 \% \quad 7 \% \quad 3 \% \quad 6.0 \mathrm{~g} \quad 26.9 \% \quad 0.22 \% \quad 4.12 \% \quad 90.91 \%$
$25 \mathrm{~g} \quad 9 \% \quad 3 \% \quad 6.5 \mathrm{~g} \quad 29.1 \% \quad 0.21 \% \quad 6.09 \% \quad 92.06 \%$ $25 \mathrm{~g} \quad 11 \% \quad 3 \% \quad 7.0 \mathrm{~g} \quad 31.4 \% \quad 0.21 \% \quad 4.13 \% \quad 92.50 \%$

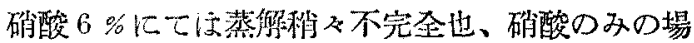

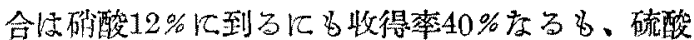
を用ふる殇合は步留りの減少は著るし。

\section{（B）栖材の場合(樽材の水分 $9.8 \%)$}

\section{（1）硝酸の双の場合}

\begin{tabular}{|c|c|c|c|c|c|c|}
\hline 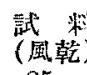 & & $\begin{array}{l}\text { 步留口 } \\
\text { (乾燥) }\end{array}$ & 收得倅 & 灰分 & ペント & $\begin{array}{l}\alpha-セ n \\
\square-ス\end{array}$ \\
\hline $25 \mathrm{~g}$ & 4 & $8.48 \mathrm{~g}$ & $37.6 \%$ & $0.36 \%$ & $9.64 \%$ & $89.19 \%$ \\
\hline & 6 & $7.42 \mathrm{~g}$ & $32.9 \%$ & $0.35 \%$ & $9.48 \%$ & $89.12 \%$ \\
\hline & 8 & $6.74 \mathrm{~g}$ & $29.9 \%$ & $0.33 \%$ & $7.36 \%$ & $90.84 \%$ \\
\hline & 10 & $6.63 \mathrm{~g}$ & $29.4 \%$ & $0.32 \%$ & $4.32 \%$ & \\
\hline & 12 & $6.52 \mathrm{~g}$ & $28.9 \%$ & $0.33 \%$ & $3.49 \%$ & $91.44 \%$ \\
\hline
\end{tabular}

$4 \%$ 确酸にては裡解不完全疗りを、6\%に到れば放 ルど米蒸解の部分を認め方。

（2）混酸老用心子場合

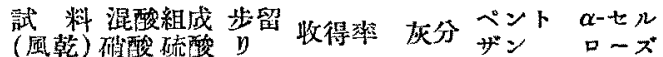

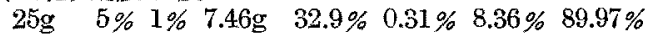
$25 \mathrm{~g} \quad 2 \% \quad 1 \% \quad 7.00 \mathrm{~g} \quad 30.9 \% \quad 0.32 \% \quad 7.25 \% 91.23 \%$ $25 \mathrm{~g} \quad 9 \% \quad 1 \% \quad 7.00 \mathrm{~g} \quad 30.9 \% \quad 0.31 \% \quad 6.63 \% \quad 90.45 \%$ $\begin{array}{llllllll}25 \mathrm{~g} & 11 \% & 1 \% & 6.92 \mathrm{~g} & 30.5 \% & 0.29 \% & 7.12 \% & 90.56 \%\end{array}$ $25 \mathrm{~g} \quad 4 \% \quad 2 \% \quad 8.05 \mathrm{~g} \quad 35.5 \% \quad 0.35 \% \quad 8.34 \% \quad 89.74 \%$ $25 \mathrm{~g} \quad 6 \% 2 \% \quad 7.00 \mathrm{gg} \quad 30.9 \% \quad 0.34 \% \quad 7.20 \% \quad 92.42 \%$ $25 \mathrm{~g} \quad 8 \% \quad 2 \% \quad 7.00 \mathrm{~g} \quad 30.9 \% \quad 0.33 \% \quad 6.80 \% \quad 92.59 \%$ $25 \mathrm{~g} \quad 10 \% \quad 2 \% \quad 6.92 \mathrm{~g} \quad 30.5 \% \quad 0.24 \% \quad 4.20 \% \quad 93.01 \%$ $25 \mathrm{~g} \quad 5 \% \quad 3 \% \quad 8.16 \mathrm{~g} \quad 36.0 \% \quad 0.25 \% \quad 7.53 \% \quad 89.22 \%$ $25 \mathrm{~g} \quad 7 \% \quad 3 \% 7.46 \mathrm{~g} \quad 32.9 \% \quad 0.27 \% \quad 7.23 \% \quad 91.38 \%$ $25 \mathrm{~g} \quad 9 \% \quad 3 \% \quad 6.92 \mathrm{~g} \quad 30.5 \% \quad 0.23 \% \quad 5.60 \% \quad 91.31 \%$ $25 \mathrm{~g} \quad 4 \% \quad 4 \% \quad 8.9 \mathrm{rg} \quad 39.6 \% \quad 0.26 \% \quad 6.67 \% \quad 89.07 \%$ $25 \mathrm{~g} \quad 6 \% \quad 4 \% \quad 7.82 \mathrm{~g} \quad 34.5 \% \quad 0.23 \% \quad 6.32 \% \quad 89.27 \%$ $25 \mathrm{~g} \quad 8 \% \quad 4 \% \quad 7.28 \mathrm{~g} \quad 31.9 \% \quad 0.21 \% \quad 5.66 \% \quad 91.30 \%$ 
上上の結果より見るに槡材、山毛譽材より确酸 法によりて得らるなバルプは火㨫に於いて网省相 似をる結果を示す。更に网者の比較をするに山法 櫸材よりのパスプは槱材よりの灰分や〉少く、步 留也や多し、然し乍的蒸解や小困醮也、次にこの 雨者老䣄葉樹パハプ人繊用に比するに、灰分 $0.1 \%$ 前後多く、ペントザンは硝酸 $10 \%$ 位を用ひざる限 b $5 \%$ 以下減少せず、乙礼原料中のペントザン 既に針葉樹より遥加反多量なるに位ることその一

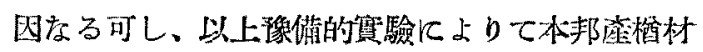

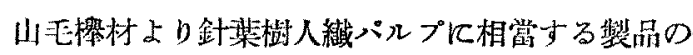
得らるってとを䜅めらる。

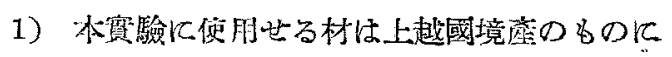
して伐探後約一ら年を經をるるす也。 